\title{
The Promise of Integrins as Effective Targets for Anticancer Agents
}

\author{
William L. Rust, ${ }^{1 *}$ Stephen W. Carper, ${ }^{1}$ and George E. Plopper ${ }^{2 \dagger}$ \\ ${ }^{1}$ UNLV Cancer Institute and Chemistry Department, University of Nevada, Las Vegas, NV 89154, USA \\ ${ }^{2}$ Department of Biology, Rensselaer Polytechnic Institute, 110 8th Street, Troy, NY 12180-3590, USA
}

Received 28 January 2002; revised 27 March 2002; accepted 28 March 2002

\begin{abstract}
This review will briefly describe integrin function, address why integrins are attractive targets for chemotherapeutic drug design, and discuss some ongoing studies aimed at inhibiting integrin activity. Integrins are cell surface heterodimeric receptors. They modulate many cellular processes including: growth, death (apoptosis), adhesion, migration, and invasion by activating several signaling pathways. Many potential chemotherapeutic agents target integrins directly (eg, polypeptides, monoclonal antibodies, adenovirus vectors). These agents may be clinically useful in controlling the metastatic spread of cancer.
\end{abstract}

\section{INTRODUCTION}

The primary therapy for most solid tumors is surgical resection, followed by a combination of radiation and chemotherapy. Most of the currently used chemotherapeutic agents target the rapidly dividing cells. However, many solid tumors are not rapidly dividing and thus evade these agents. Often, tumors that resist or evade chemotherapy treatments continue to grow, and may spread to other, distant organs, resulting in the formation of secondary tumors (metastases). Once a cancer develops to this stage, patient prognosis is usually very poor. Novel chemotherapeutic agents need to be developed to help control the growth and spread of metastatic tumors. In this review, we discuss the potential value of integrins as chemotherapeutic targets. The function of integrins in cancer progression is addressed, followed by a discussion of current drug discovery efforts and clinical trials of compounds that specifically target integrin receptors.

The latest generation of chemotherapeutic agents is designed to target molecules required for survival by cancerous cells but not by normal cells. One very interesting group of molecules that are receiving attention is the integrin family of cell surface adhesion receptors. In the past ten years, it has become clear that the integrins play an important role in virtually every stage of cancer progression. In addition, oncogenic transformation is often accompanied by changes in integrin expression and substrate preference. Although integrins are not oncoproteins, they modulate the processes of cell growth, death, migration, and invasion, which all impinge on the severity of clinical disease [1]. Several drugs in clinical trials function as integrin antagonists; all having shown promise as antiangiogenic, antimetastatic, and antiproliferative compounds in mouse models [2].

\section{INTEGRIN STRUCTURE AND FUNCTION}

Integrins are a family of heterodimeric cell surface receptors. The known $18 \alpha$ and $8 \beta$ subunits combine to form at least $24 \alpha \beta$ heterodimers (for recent reviews see references $[2,3,4])$. Most cells express more than one type of integrin heterodimer. Integrin expression profiles are unique for distinct cell types, and change with developmental stage and physiological conditions within a cell type [5]. Most integrins mediate cell/substratum adhesion by binding to extracellular matrix (ECM) proteins, while a few mediate cell-cell adhesion via homotypic or heterotypic coupling with other cell surface receptors. This family of receptors can be classified into three subfamilies. The $\beta 1$ integrins generally mediate interactions between cells and ECM. The $\beta 2$ integrins are restricted to leukocytes and are typified by having other cell surface proteins as their ligands. The $\beta 3$ integrins are almost exclusively expressed on platelets and megakaryocytes and act as important mediators of platelet adhesion [6]. Excepting the fibronectin receptor $\alpha 5 \beta 1$, all integrins bind to more than one ligand. Each ECM molecule is also bound by more than one integrin. Although it is impossible to predict an integrin binding site based on sequence, an acidic residue is common to all known binding sites, and many contain the sequence RGD [2].

At sites of integrin activation and clustering, protein aggregates termed focal complexes and focal adhesions assemble on the intracellular surface. The types of proteins that form these complexes can be grouped as either structural, which form links to the actin cytoskeleton, or signaling, which include a variety of kinases and adapter molecules linking integrins to other kinases, members of the GTPase families, lipid kinases and phospolipases, and ion channels $[7,8]$. The structural components are talin, $\alpha$-actinin, 
vinculin, and filamin. Of these, only $\alpha$-actinin binds directly to integrins, while the others are capable of binding each other and members of the signaling component $[9,10]$. These complexes are sites where the cell can generate tension with respect to its surroundings, allowing the cell to alter its shape and carry out complex processes such as migration and cell division [2].

\section{INTEGRIN CLUSTERS ARE SIGNALING COMPLEXES}

The signaling proteins found at focal complexes and focal adhesions associate with integrin cytoplasmic domains to form a nexus for stimulating intracellular signaling cascades. At these sites, signaling from outside to inside the cell occurs, which contributes to the regulation of diverse cellular processes including entry into the cell cycle, programmed cell death (apoptosis), gene transcription, regulation of intracellular $\mathrm{pH}$, differentiation, and migration. A summary of the known signaling pathways associated with integrin receptors is presented in Figure 1. Signaling through integrins from the inside to the outside of the cell regulates adhesive strength through affinity and avidity modulation, and helps in the remodeling of the ECM during tissue development and tissue invasion. Exactly how this occurs is unknown, but phosphorylation of integrin subunits may be important in both processes [6].

The $125 \mathrm{kda}$ kinase termed focal adhesion kinase (FAK) is the best characterized of the integrin-associated signaling proteins. FAK binds to integrin receptors and plays a central role in assembling complexes of signaling proteins at the cell surface. FAK has numerous tyrosine residues that, when phosphorylated, act as docking sites for the recruitment and activation of several SH2- and SH3-containing classes of signaling molecules. Talin and paxillin are implicated in the activation of FAK by stimulating its autophosphorylation on Y397. This opens a binding site for the oncoprotein Src. All three of these molecules are implicated in targeting FAK to the focal adhesion. Src also phosphorylates FAK on a number of residues, including Y925. The adaptor protein Grb2 binds to phosphorylated Y397, and through the action of the guanine nucleotide exchange factor SOS, connects activated receptor tyrosine kinases to Ras/ERK/MAP kinase cascades, [2, 4, 8, 11]. Phosphatidyl Inositol 3-Kinase (PI$3 \mathrm{~K}$ ) also binds to Y397, and mediates cell proliferation, cell migration, and apoptosis through its downstream effector $\mathrm{PKB} /$ Akt $[3,5]$. The adaptor protein $\mathrm{p} 130^{\mathrm{CAS}}$ is a substrate of the FAK/Src complex and is implicated in activating the ERK cascade as well as Jun N-terminal kinase (JNK). Both p130 ${ }^{\mathrm{CAS}}$ and FAK are thought to use the ERK pathway to activate several transcription factors [4]. FAK is also implicated in controlling cell cycle progression and preventing apoptosis through a pathway involving protein kinase $\mathrm{C}$, phospholipase A2, and p53 [4, 12].

Integrin regulated signaling proteins that can be activated independently of FAK include protein kinase $\mathrm{C}$, integrin linked kinase, integrin associated protein, and the tetraspan (TMS4F) adapter proteins $[2,11]$. Integrin linked kinase appears to phosphorylate only integrin subunits, and may function as a bridge to FAK [2]. Although tetraspans can regulate cell motility, their mechanism of action is not understood.

\section{INTEGRINS CONTRIBUTE TO CANCER PROGRESSION}

Integrins act to promote the growth, and retard the death, of both normal and tumorigenic cells. In cooperation with growth factor receptors, they induce proliferation by specifically causing the transcription of the cyclins and cyclin dependent kinases (Cdks) required for transition past the G1 checkpoint, and by down-regulation of Cdk inhibitors $[2,6,12]$. The fact that most cells deprived of ECM interactions undergo apoptosis (programmed cell death), and that integrin ligation can rescue those cells, demonstrates that integrins are involved in stimulating apoptosis resistance mechanisms [2]. For instance, in some cell lines, integrins activate transcription of the $\mathrm{Bcl}-2$ gene and increase the activity of MAPK, JNK, PI-3 kinase, and PKB/Akt, all of which are known to inhibit apoptosis $[2,3,5,6]$. Lastly, cell death by deprivation of engagement of ECM (anoikis) may be an important control mechanism in cancer since carcinoma cells that lose contact with the matrix would die rather than circulate and colonize distant sites $[3,5]$. Hence, changes in the integrin expression profiles may dramatically influence the progression of malignant tumors.

Benign tumors are encapsulated by an organized lattice of basement membrane components. The progression to malignancy, and the clinical diagnosis of malignant disease, is essentially determined by the capability of tumor cells to dissociate, degrade the lattice, and metastasize to other locations within the body. This process, termed the metastatic cascade, begins with the detachment of single tumor cells and active infiltration of those cells into the surrounding stroma where entry into the vasculature and lymphatic system is possible. Dissociation of individual cells from a tumor mass is regulated by the E-cadherin family of receptors. These are shown to be suppressors of epithelial tumor metastasis. Recently, activation of integrin $\alpha 3 \beta 1$ was shown to down-regulate Ecadherin mediated adhesion, causing loss of cell-cell adhesion, junctional communication, and enhancing invasiveness of malignant tumor cells [13]. For invasion by dissociated cells to occur, the ECM that surrounds the neoplastic tissue must be degraded to allow the escape of invasive cells. Integrins participate in the ECM degradation by stimulating the secretion of ECM-degrading proteases such as matrix metalloproteases, and enhancing invasion through a signaling cascade involving Ras [2, 3].

\section{INTEGRINS AS THERAPEUTIC MARKERS}

The large number of investigations into the effectiveness of integrins as indicators of disease and as an aid to noninvasive cancer imaging underline the potential usefulness of these receptors in the clinic. Several recent studies show that both up-regulation and down-regulation of 


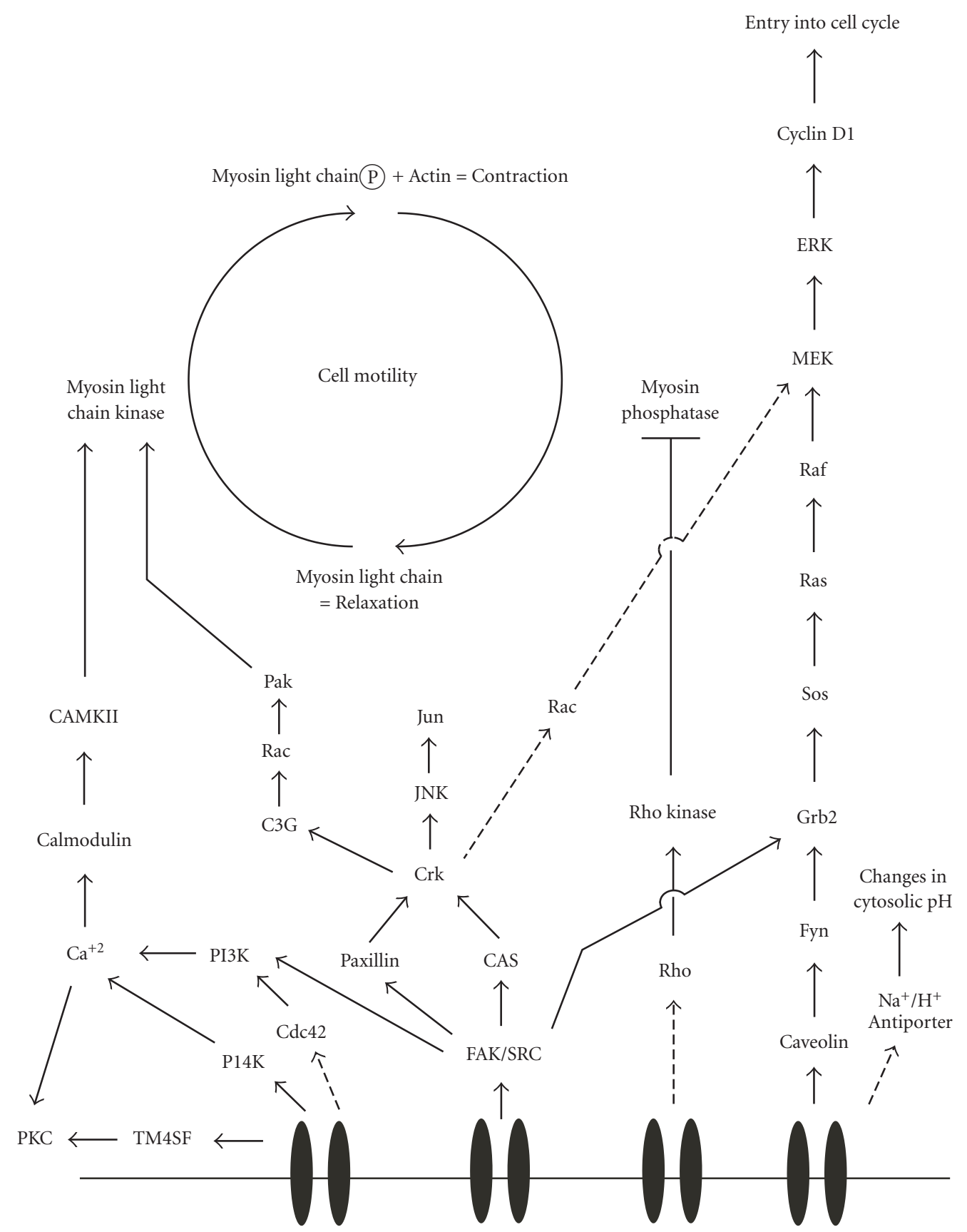

FiguRE 1. Schematic of known integrin-associated signaling pathways. Solid arrows indicate direct association between signaling partners, while dashed arrows indicate associations that may involve the action of unidentified intermediates. Abbreviations: CAMKII, Calmodulin dependent protein kinase II; CAS, Crk-associtaed substrate; FAK, focal adhesion kinase; JNK, Jun kinase; Myosin Light Chain-P, phosphorylated myosin light chain; PI3K and PI4K, phosphatidyl inositol 3 (or 4) kinase; PKC, protein kinase C; TM4SF, tetraspan superfamily of proteins.

integrin expression can be effective markers of incidence of disease and patient prognosis. A comparison of normal and neoplastic human prostate tissues showed a downregulation of a specific variant of the $\beta 1$ integrin subunit [14], and strong evidence shows that reduced expression of $\alpha 6$ and $\beta 4$ may contribute to the higher tumorigenicity of androgen-independent prostate tumor cells [15]. In a study of metastatic melanoma, longer disease free survival and overall survival correlated with $\beta 1$ expression [16], while neuroblastoma aggressiveness was correlated with expression of integrin $\alpha \mathrm{v} \beta 3$ and $\alpha \mathrm{v} \beta 5$ by the microvascular endothelium [17]. Studies of acute lymphoblastic leukemia show that $\beta 2$ expression was significantly associated with splenomegaly [18], and expression of $\alpha 5 \beta 1$ was associated with positive response to chemotherapy in patients with rectal cancer [19]. Finally, node negative nonsmall cell lung cancer patients 
whose tumors over-express integrin $\alpha 5$ had a lower survival rate than those whose did not [20].

These clinical correlations of patient biopsies to integrin expression are recapitulated to some degree in rodent and in vitro analyses. For example, a study of rat hepatocarcinogenesis showed that integrins $\alpha 1$ and $\alpha 5$ were up-regulated in metastases of the lung and diaphragm, while integrins $\alpha 1$, $\alpha 2, \alpha 3$, and $\alpha 5$ were decreased in the primary carcinoma and preneoplastic nodules [21]. Among pancreatic cancer cell lines, those that showed a higher potential to metastasize in a mouse model had enhanced the expression of $\alpha \mathrm{v} \beta 5$ while those that did not metastasize had enhanced expression of $\alpha 3$ [22]. The expression of $\beta 4$ was inversely correlated with dissemination of ten human gastric cancer cells lines in SCID mice [23], and two of three human epithelial ovarian cancer cell lines could be identified by the high expression of $\alpha \mathrm{v} \beta 6$ integrin, which was correlated with integrin-linked signaling and protease secretion [24]. The development of endometrial cancers has been linked to the loss of progesterone receptors. It was found that re-expressing an isoform of that receptor inhibited both the expression of integrin subunits $\alpha 3, \beta 1$, and $\beta 3$, and inhibited cell invasion into matrigel [25].

In addition to the cases mentioned above, integrin expression can also be specific to levels of tumor resistance to common anticancer chemotherapies. Gastrointestinal tumor cells selected for resistance to 5-fluorouracil showed marked under-expression of the integrin $\alpha 3$ [26], while human ovarian cancer cell lines resistant to the fenretinide were associated with reduced expression of $\beta 1$ integrin [27]. A nasal carcinoma cell line resistant to melphalan showed increased expression of $\alpha 2, \alpha 5, \alpha 6$, and $\beta 4$, decreased expression of $\alpha 4$ and exhibited enhanced invasion in vitro [28]. Glioma cell lines resistant to vincristine, doxorubicin, and etoposide showed enhanced expression of integrins $\alpha 2, \alpha 3, \alpha 5$, and $\beta 1$ [29].

If the integrin receptors expressed by a particular tumor are reproducibly correlated with patient prognosis, that knowledge can be used by the clinician to choose the appropriate therapeutic regimen. Noninvasive imaging based on integrin expression is potentially useful not only to identify particular types of tumors but also to assess their responsiveness to particular drugs or drug-targeting methods. In two recent studies, a glycopeptide containing the integrin binding domain RGD was found in tumor mouse models to be suitable for tumor visualization and determination of integrin status [30], and a similar peptide specifically bound to $\alpha \mathrm{v} \beta 3$ expressing tumors in vivo [31].

\section{INTEGRINS AS TARGETS FOR DRUG DELIVERY AND GENE THERAPY}

Achieving tissue-specific drug delivery is the primary challenge faced by researchers in the fields of gene therapy, targeted drug delivery, and immune meditated tumor destruction. Integrin expression can both provide solutions to and exacerbate the difficulty of this problem. An excellent example is the use of recombinant adenoviruses that interact with cell surface integrins. Some adenoviruses are successfully internalized into host cells by forming complexes with the host proteins CAR (Coxsackie B virus and Ad Receptor) and integrins $\alpha \mathrm{v} \beta 3$ and $\alpha \mathrm{v} \beta 5$ [32]. The semispecific expression of these proteins makes targeting difficult. In some cases, replacing the binding capacities of the viral capsid may prove to be effective, while in others it may be effective to enhance the integrin binding capacities. Using the former strategy, an adenoviral vector targeted solely to the human epidermal growth factor receptor showed improved targeting to tumors of the brain [33]. But an adenovirus vector targeted to CAR, epidermal growth factor receptor, and $\alpha \mathrm{v}$ integrins via the RGD peptide showed enhanced gene transfer efficiency to pancreatic carcinoma and glioma cells $[34,35]$. In a study of adenoviral gene transfer efficiency in ovarian cancer cells, poorly infected cell lines showed no expression of $\alpha \mathrm{v} \beta 3$ integrins, and re-expression of these receptors increased adenoviral infection [36]. In order to target cells not expressing CAR nor $\alpha \mathrm{v}$ integrins, an antibody specific for the adenoviral vector was fused with recombinant growth factors to serve as a bridge for targeted infection [37]. Recently, integrin receptors expressed in large numbers on most ovarian cancers $(\alpha \mathrm{v} \beta 3$ and $\alpha \mathrm{v} \beta 5)$ were used as binding targets for adenovirus vectors containing the herpes simplex virus thymidine kinase gene for molecular chemotherapy [38]. These vectors were very effective against purified primary ovarian cancer cells and may be a useful agent for treating ovarian cancer in clinical trials.

Another example is the targeting and activation of lymphoid cells to tumor sites, which depend upon binding to integrin receptors. This binding can be modulated by secreted chemokines [39]. In a unique mixture of strategies, infection of mice with adenovirus carrying IL-12 gene and targeted to $\alpha \mathrm{v} \beta 3$ integrin expressed on liver metastases led to enhanced recruitment of adoptively transferred cytolytic T lymphocytes [40]. In another case, a human transitional cell carcinoma cell line transfected to over-express IL- 6 showed concomitant increases in $\alpha 5$ and $\beta 1$ expression, which increased the adherence of tumor destroying cells of bacillus CalmetteGuerin therapy [41]. A chimeric cell adhesion molecule containing the $\alpha \mathrm{v} \beta 3$ disintegrin kistrin and CD31/PECAM-1 served as a bridge to home adoptively transferred lymphoid cells to angiogenic endothelial cells and caused the accumulation of lymphoid cells to angiogenic tumors in Lewis lung and melanoma mice models [42].

Finally, in an effort to target a recombinant virus that does not use integrins in the process of internalization, a capsid of the feline panleukopenia virus was modified to express the RGD motif to bind $\alpha \mathrm{v}$ integrins. This successfully contributed to directing infection of those particles to a human rhabdomyosarcoma cell line [43].

\section{NONVIRAL STRATEGIES FOR DISRUPTING INTEGRINS}

Nonviral and nonlymphoid strategies for integrinspecific tumor targeting focus on integrin-specific antibodies, soluble integrin ligands, or vectors that encode cyclic glycopeptides that contain the integrin binding RGD sequence. 
A vector with the RGD motif was found to preferentially colocalize to tumor tissues over the lung, kidney, and spleen in nude mice [44]. In lysosomal vectors that resemble retroviral envelopes but are not-toxic, this motif was shown to aid transduction of human melanoma cells [45]. The antimicrobial peptide tachyplesin coupled to this motif was effective in inhibiting the growth of tumors in a mouse model and inducing apoptosis of prostate cancer cells in vitro [46]. Alone, an RGD containing peptide caused anoikis of glioblastoma cell lines and prolonged the survival of SCID mice with intracranial tumors [47]. And finally, RGD containing peptides have shown promise as drug delivery agents for radiotherapy. This is thought to be effective because irradiated tumor blood vessels are found to have activated $\alpha \mathrm{IIb} \beta 3$ integrins. At least one of these peptides, biapcitide is currently in clinical trials [48].

Disintegrin is the name given to soluble integrin ligands (originally isolated from snake venom) that disrupt cellmatrix interactions [49]. One disintegrin, contortrostatin, disrupts cytoskeletal structure and hence inhibits cell motility, raising the possibility that these compounds may be useful for therapeutic intervention for cancer invasion and metastasis [50].

Abciximab is a mouse-human chimeric monoclonal Fab fragment approved for adjunct therapy for the prevention of cardiac coronary intervention. Abciximab binds to the integrin $\alpha_{\mathrm{IIb}} \beta 3$ (GPIIbIIIa) receptor on platelets, which is the major adhesion receptor involved in aggregation. It also binds two other integrin receptors: the $\alpha \mathrm{v} \beta 3$ receptor (present in high density on activated endothelial and smooth muscle cells) and $\alpha \mathrm{M} \beta 2$ integrin (present on activated leukocytes) [51]. It is reasonable to assume that Abciximab may have antimetastatic properties in cases of tumors that express the above integrin receptors.

The specificity of these inhibitors varies for different types of integrins. Therefore, to develop and then effectively utilize an anti-integrin therapy, the type of integrin and/or effectiveness of each agent or combination of agents must be measured. We have developed a fluorescence-based automated assay for identifying antimigratory compounds with the ability to discern cytotoxic from noncytotoxic modes of action that can achieve this goal [52]. The assay utilizes a chambered well that can be used to simultaneously measure migration and viability of cells following treatment with inhibitors. This enables us to assay the effects of compounds that disrupt integrins directly, or that interfere with downstream signaling events following integrin ligation. For example, with this assay we have been able to show that carboxyamidotriazole, a calcium channel blocker, inhibits chemotactic and haptotactic migration of breast cancer cells more effectively than tamoxifen (an antiestrogen). This assay should increase the ability to rapidly screen chemical libraries for even more compounds that inhibit integrin function.

These are but a few examples of agents currently in development to target integrins as anticancer therapies. These agents hold the promise of being effective, selective, and highly tolerable in adjuvant therapies.

\section{ACKNOWLEDGMENTS}

This work was supported by a career development grant DAMD17-98-1-8325 to GEP and a predoctoral grant DAMD17-00-1-0363 to WLR from the United States Army Breast Cancer Research Program.

\section{REFERENCES}

[1] Engers R, Gabbert HE. Mechanisms of tumor metastasis: cell biological aspects and clinical implications. $J$ Cancer Res Clin Oncol. 2000;126(12):682-692.

[2] Berman AE, Kozlova NI. Integrins: structure and functions. Membr Cell Biol. 2000;13(2):207-244.

[3] Parise LV, Lee J, Juliano RL. New aspects of integrin signaling in cancer. Semin Cancer Biol. 2000;10(6):407414.

[4] Zhao JH, Guan JL. Role of focal adhesion kinase in signaling by the extracellular matrix. Prog Mol Subcell Biol. 2000;25:37-55.

[5] Mercurio AM, Bachelder RE, Rabinovitz I, O'Connor KL, Tani T, Shaw LM. The metastatic odyssey: the integrin connection. Surg Oncol Clin N Am. 2001;10(2):313-328.

[6] Coppolino MG, Dedhar S. Bi-directional signal transduction by integrin receptors. Int J Biochem Cell Biol. 2000;32(2):171-188.

[7] Ivaska J, Heino J. Adhesion receptors and cell invasion: mechanisms of integrin-guided degradation of extracellular matrix. Cell Mol Life Sci. 2000;57(1):16-24.

[8] Parsons JT, Martin KH, Slack JK, Taylor JM, Weed SA. Focal adhesion kinase: a regulator of focal adhesion dynamics and cell movement. Oncogene. 2000;19(49):5606-5613.

[9] Turner CE. Paxillin and focal adhesion signalling. Nat Cell Biol. 2000;2(12):E231-E236.

[10] Calderwood DA, Shattil SJ, Ginsberg MH. Integrins and actin filaments: reciprocal regulation of cell adhesion and signaling. J Biol Chem. 2000;275(30):22607-22610.

[11] Hulleman E, Boonstra J. Regulation of G1 phase progression by growth factors and the extracellular matrix. Cell Mol Life Sci. 2001;58(1):80-93.

[12] Assoian RK, Schwartz MA. Coordinate signaling by integrins and receptor tyrosine kinases in the regulation of G1 phase cell-cycle progression. Curr Opin Genet Dev. 2001;11(1):48-53.

[13] Kawano K, Kantak SS, Murai M, Yao CC, Kramer RH. Integrin $\alpha 3 \beta 1$ engagement disrupts intercellular adhesion. Exp Cell Res. 2001;262(2):180-196.

[14] Perlino E, Lovecchio M, Vacca RA, et al. Regulation of mRNA and protein levels of betal integrin variants in human prostate carcinoma. Am J Pathol. 2000;157(5):1727-1734.

[15] Bonaccorsi L, Carloni V, Muratori M, et al. Androgen receptor expression in prostate carcinoma cells suppresses alpha6beta4 integrin-mediated invasive phenotype. Endocrinology. 2000;141(9):3172-3182.

[16] Vihinen P, Nikkola J, Vlaykova T, et al. Prognostic value 
of betal integrin expression in metastatic melanoma. Melanoma Res. 2000;10(3):243-251.

[17] Erdreich-Epstein A, Shimada H, Groshen S, et al. Integrins alpha $(\mathrm{v})$ beta3 and alpha(v)beta5 are expressed by endothelium of high-risk neuroblastoma and their inhibition is associated with increased endogenous ceramide. Cancer Res. 2000;60(3):712-721.

[18] Mengarelli A, Zarcone D, Caruso R, et al. Adhesion molecule expression, clinical features and therapy outcome in childhood acute lymphoblastic leukemia. Leuk Lymphoma. 2001;40(5-6):625-630.

[19] Jayne DG, Heath RM, Dewhurst O, Scott N, Guillou PJ. Extracellular matrix proteins and chemoradiotherapy: $\alpha 5 \beta 1$ integrin as a predictive marker in rectal cancer. Eur J Surg Oncol. 2002;28(1):30-36.

[20] Adachi M, Taki T, Higashiyama M, Kohno N, Inufusa H, Miyake M. Significance of integrin alpha5 gene expression as a prognostic factor in node-negative nonsmall cell lung cancer. Clin Cancer Res. 2000;6(1):96101.

[21] Yuan ST, Hu XQ, Lu JP, KeiKi H, Zhai WR, Zhang YE. Changes of integrin expression in rat hepatocarcinogenesis induced by $3^{\prime}$-Me-DAB. World J Gastroenterol. 2000;6(2):231-233.

[22] Nishimori H, Yasoshima T, Hata F, et al. A novel nude mouse model of liver metastasis and peritoneal dissemination from the same human pancreatic cancer line. Pancreas. 2002;24(3):242-250.

[23] Ishii Y, Ochiai A, Yamada T, et al. Integrin $\alpha 6 \beta 4$ as a suppressor and a predictive marker for peritoneal dissemination in human gastric cancer. Gastroenterology. 2000;118(3):497-506.

[24] Ahmed N, Pansino F, Baker M, Rice G, Quinn M. Association between alphavbeta6 integrin expression, elevated p42/44 kDa MAPK, and plasminogen-dependent matrix degradation in ovarian cancer. J Cell Biochem. 2002;84(4):675-686.

[25] Zhang GJ, Crist SA, McKerrow AK, Xu Y, Ladehoff DC, See WA. Autocrine IL-6 production by human transitional carcinoma cells upregulates expression of the $\alpha 5 \beta 1$ fibronectin receptor. J Urol. 2000;163(5):15531559.

[26] Takechi T, Koizumi K, Tsujimoto H, Fukushima M. Screening of differentially expressed genes in 5fluorouracil-resistant human gastrointestinal tumor cells. Jpn J Cancer Res. 2001;92(6):696-703.

[27] Appierto V, Cavadini E, Pergolizzi R, et al. Decrease in drug accumulation and in tumour aggressiveness marker expression in a fenretinide-induced resistant ovarian tumour cell line. $\mathrm{Br} J$ Cancer. 2001;84(11):1528-1534.

[28] Liang Y, Meleady P, Cleary I, McDonnell S, Connolly L, Clynes M. Selection with melphalan or paclitaxel (Taxol) yields variants with different patterns of multidrug resistance, integrin expression and in vitro invasiveness. Eur J Cancer. 2001;37(8):1041-1052.

[29] Hikawa T, Mori T, Abe T, Hori S. The ability in adhesion and invasion of drug-resistant human glioma cells.
J Exp Clin Cancer Res. 2000;19(3):357-362.

[30] Haubner R, Wester HJ, Weber WA, et al. Noninvasive imaging of alpha(v)beta3 integrin expression using 18F-labeled RGD-containing glycopeptide and positron emission tomography. Cancer Res. 2001;61(5):1781-1785.

[31] Haubner R, Wester HJ, Burkhart F, et al. Glycosylated RGD-containing peptides: tracer for tumor targeting and angiogenesis imaging with improved biokinetics. $J$ Nucl Med. 2001;42(2):326-336.

[32] Davison E, Kirby I, Whitehouse J, Hart I, Marshall JF, Santis G. Adenovirus type 5 uptake by lung adenocarcinoma cells in culture correlates with Ad5 fibre binding is mediated by alpha(v)betal integrin and can be modulated by changes in betal integrin function. J Gene Med. 2001;3(6):550-559.

[33] van Beusechem VW, Grill J, Mastenbroek DC, et al. Efficient and selective gene transfer into primary human brain tumors by using single-chain antibody-targeted adenoviral vectors with native tropism abolished. $J$ Virol. 2002;76(6):2753-2762.

[34] Wesseling JG, Bosma PJ, Krasnykh V, et al. Improved gene transfer efficiency to primary and established human pancreatic carcinoma target cells via epidermal growth factor receptor and integrin-targeted adenoviral vectors. Gene Ther. 2001;8(13):969-976.

[35] Grill J, van Beusechem VW, Van Der Valk P, et al. Combined targeting of adenoviruses to integrins and epidermal growth factor receptors increases gene transfer into primary glioma cells and spheroids. Clin Cancer Res. 2001;7(3):641-650.

[36] Bruning A, Kohler T, Quist S, et al. Adenoviral transduction efficiency of ovarian cancer cells can be limited by loss of integrin beta3 subunit expression and increased by reconstitution of integrin alphavbeta3. Hum Gene Ther. 2001;12(4):391-399.

[37] Li E, Brown SL, Von Seggern DJ, Brown GB, Nemerow GR. Signaling antibodies complexed with adenovirus circumvent CAR and integrin interactions and improve gene delivery. Gene Ther. 2000;7(18):1593-1599.

[38] Hemminki A, Belousova N, Zinn KR, et al. An adenovirus with enhanced infectivity mediates molecular chemotherapy of ovarian cancer cells and allows imaging of gene expression. Mol Ther. 2001;4(3):223-231.

[39] Fujiwara H, Hamaoka T. Coordination of chemokine and adhesion systems in intratumoral $\mathrm{T}$ cell migration responsible for the induction of tumor regression. Int Immunopharmacol. 2001;1(4):613-623.

[40] Mazzolini G, Narvaiza I, Bustos M, et al. Alpha(v)beta(3) integrin-mediated adenoviral transfer of interleukin-12 at the periphery of hepatic colon cancer metastases induces VCAM-1 expression and T-cell recruitment. Mol Ther. 2001;3(5 part 1):665-672.

[41] Zhang GJ, Crist SA, McKerrow AK, Xu Y, Ladehoff DC, See WA. Autocrine IL-6 production by human transitional carcinoma cells upregulates expression of the $\alpha 5 \beta 1$ fibronectin receptor. J Urol. 2000;163(5): 1553-1559. 
[42] Wiedle G, Johnson-Leger C, Imhof BA. A chimeric cell adhesion molecule mediates homing of lymphocytes to vascularized tumors. Cancer Res. 1999;59(20):52555263.

[43] Maxwell IH, Chapman JT, Scherrer LC, et al. Expansion of tropism of a feline parvovirus to target a human tumor cell line by display of an alpha(v) integrin binding peptide on the capsid. Gene Ther. 2001;8(4):324-331.

[44] Aoki Y, Hosaka S, Kawa S, Kiyosawa K. Potential tumortargeting peptide vector of histidylated oligolysine conjugated to a tumor-homing RGD motif. Cancer Gene Ther. 2001;8(10):783-787.

[45] Nahde T, Muller K, Fahr A, Muller R, Brusselbach S. Combined transductional and transcriptional targeting of melanoma cells by artificial virus-like particles. J Gene Med. 2001;3(4):353-361.

[46] Chen Y, Xu X, Hong S, et al. RGD-Tachyplesin inhibits tumor growth. Cancer Res. 2001;61(6):2434-2438.

[47] Chatterjee S, Matsumura A, Schradermeier J, Gillespie GY. Human malignant glioma therapy using anti-alpha(v)beta3 integrin agents. J Neurooncol. 2000;46(2):135-144.

[48] Hallahan DE, Qu S, Geng L, et al. Radiationmediated control of drug delivery. Am J Clin Oncol. 2001;24(5):473-480.

[49] Gould RJ, Polokoff MA, Friedman PA, et al. Disintegrins: a family of integrin inhibitory proteins from viper venoms. Proc Soc Exp Biol Med. 1990;195(2):168-171.

[50] Ritter MR, Zhou Q, Markland FS Jr. Contortrostatin, a homodimeric disintegrin, actively disrupts focal adhesion and cytoskeletal structure and inhibits cell motility through a novel mechanism. Cell Adhes Commun. 2001;8(2):71-86.

[51] Cohen SA, Trikha M, Mascelli MA. Potential future clinical applications for the GPIIb/IIIa antagonist, abciximab in thrombosis, vascular and oncological indications. Pathol Oncol Res. 2000;6(3):163-174.

[52] Rust WL, Huff JL, Plopper GE. Screening assay for promigratory/antimigratory compounds. Anal Biochem. 2000;280(1):11-19.

* Current address: Novartis Pharma AG, WSJ 386.631, CH-4002, Basel, Switzerland

† Corresponding author. E-mail: ploppg@rpi .edu Fax: +1 518276 2162; Tel: +1 5182768288 

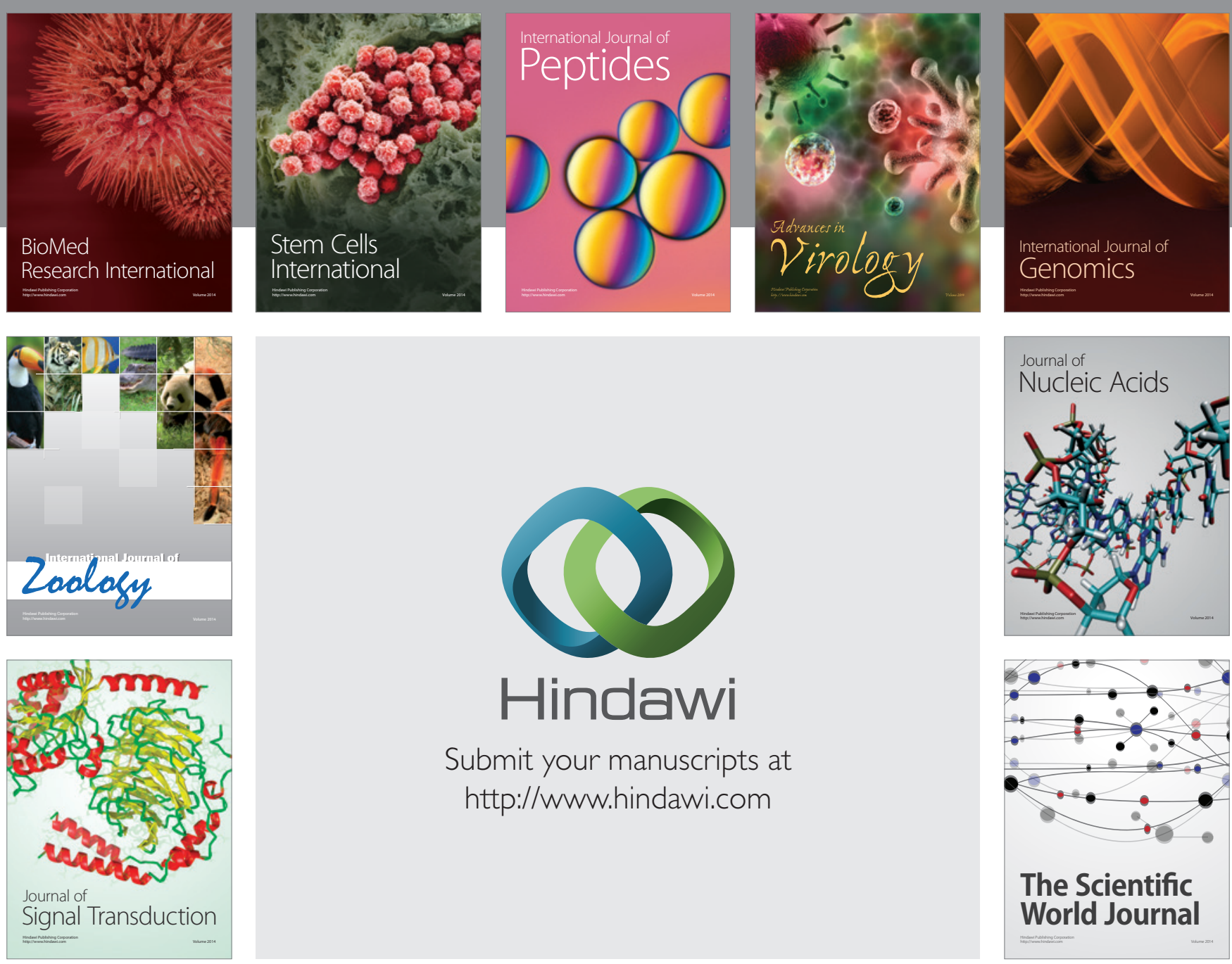

Submit your manuscripts at

http://www.hindawi.com
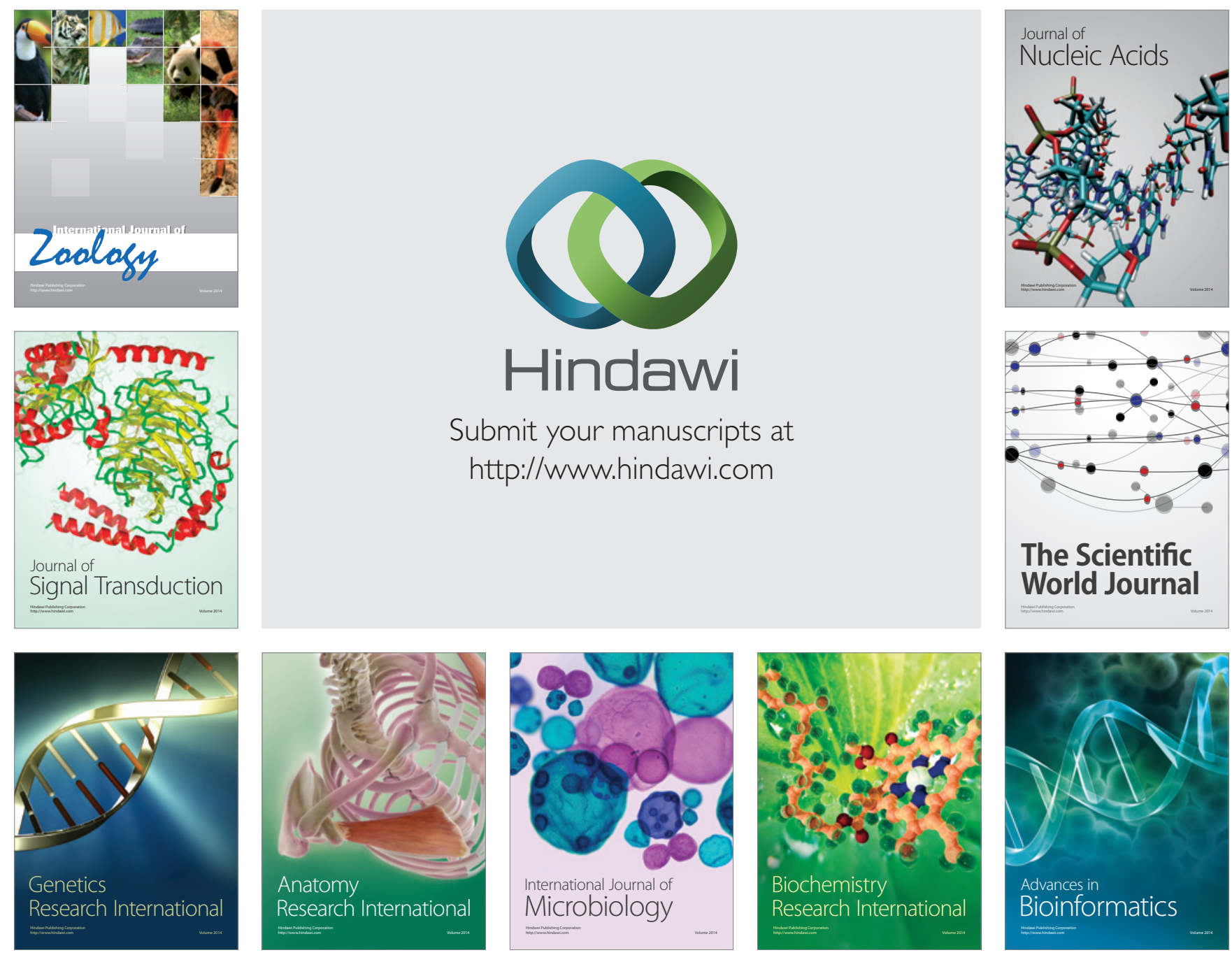

The Scientific World Journal
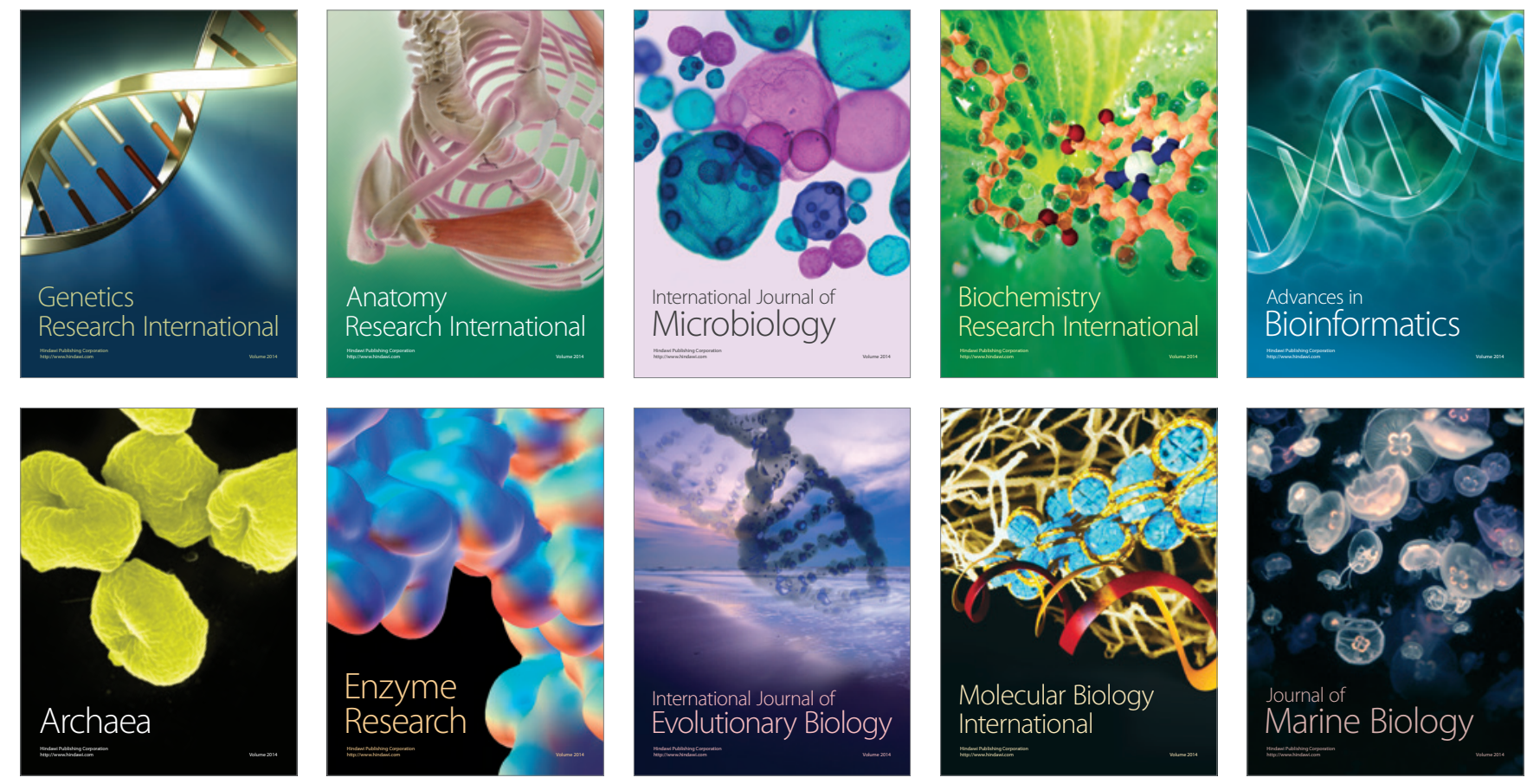